\title{
O COMÉRCIO EXTERIOR DOS AGRONEGÓCIOS BRASILEIROS EM 2008
}

\author{
Danton Leonel de Camargo Bini ${ }^{1}$ \\ José Alberto Ângelo \\ José Sidnei Gonçalves ${ }^{3}$
}

\section{Resumo}

O presente artigo apresenta os principais destinos das exportações agropecuárias brasileiras no ano de 2008. Destaca o decréscimo nas vendas dos produtos do campo brasileiro para mercados tradicionais como a União Européia e os Estados Unidos da América (EUA) e o acréscimo para países como a Rússia e Venezuela. A conclusão afirma a existência de um processo de descentralização nas exportações agropecuárias do Brasil.

Palavras-chave: exportação, agropecuária, descentralização.

\begin{abstract}
The present article introduces the principals destinations of brazilians agriculturals exports in 2008. It detaches the decrease in the sales of the products of the country for traditional market us European Union and United States of American (USA) and the increase for countries us Russian and Venezuela. The conclusion affirms the existence of decentralization's process in the brazilians agriculturals exports.
\end{abstract}

Keywords: export, agricultural, decentralization.

\footnotetext{
${ }^{1}$ Geógrafo, Mestre em Geografia Humana pelo Departamento de Geografia da Faculdade Filosofia, Letras e Ciências Humanas (FFLCH) da Universidade de São Paulo (USP), Pesquisador Científico do Instituto de Economia Agrícola (IEA) da Secretaria da Agricultura e Abastecimento do Estado de São Paulo. E-mail: danton@iea.sp.gov.br.

${ }^{2}$ Bacharel em Matemática pela Fundação Santo André, Pesquisador Científico do Instituto de Economia Agrícola (IEA) da Secretaria da Agricultura e Abastecimento do Estado de São Paulo. E-mail: alberto@iea.sp.gov.br

${ }^{3}$ Engenheiro Agrônomo, Doutor em Ciências Econômicas pela Universidade Estadual de Campinas (Unicamp), Pesquisador Científico do Instituto de Economia Agrícola (IEA) da Secretaria da Agricultura e Abastecimento do Estado de São Paulo. E-mail:sydy@iea.sp.gov.br
} 


\section{1 - Introdução}

O Brasil, desde o período colonial se caracteriza como um território especializado na exportação de matérias-primas básicas, destacando-se as oriundas do setor agropecuário. Assim, a industrialização e a diversificação da economia acontecidas no decorrer do século $\mathrm{XX}$ devem ser compreendidas como processos em parte demandados pela modernização do campo brasileiro. Data-se, para Kageyama (1990, p. 121), “a partir de meados dos anos 60 que o processo de modernização atinge uma fase mais avançada, a de industrialização da agricultura”. Através de taxas de juros subsidiadas e de grandiosos recursos obtidos pelo Sistema Nacional de Crédito Rural (SNCR), criado em 1965, articulou-se a internalização ao território brasileiro de elos antes importados em diferentes setores agropecuários, constituindo os complexos agroindustriais no país. Esses elos internalizados são as indústrias de bens de capital: máquinas (tratores, colheitadeiras, plantadeiras, caminhões), implementos (arados, grades, etc), insumos (fertilizantes, defensivos) e as agroindústrias processadoras, que são construídas e passam a funcionar dentro do país. Com essa mudança possibilitada pela estruturação de uma indústria de base brasileira e estatal - siderúrgica e metalúrgica -, rompem-se as barreiras e os limites impostos pelas importações. Onde antes nacionalmente se tinha na maioria das culturas agrícolas somente a produção da matéria-prima ${ }^{4}$, passa-se a ter todo um complexo: a "indústria para a agricultura" à montante e a agroindústria processadora à jusante do campo.

Acostumada com resultados práticos limitados, a estruturação da pesquisa e extensão rural feita pelo governo federal, com a criação no início da década de 1970 da EMBRAPA (Empresa Brasileira de Pesquisa Agropecuária) e da EMBRATER (Empresa Brasileira de Pesquisa Agropecuária), propiciou a cientifização da agricultura brasileira e a conseqüente expansão do meio técnico-científico pelo território nacional. Novos objetos técnicos (máquinas, implementos, sementes de novas variedades e insumos), enquanto “extraordinárias inovações científico-técnicas” (ELIAS, 1996, p.29) permitiram “... a introdução de certos cultivos em áreas antes inadequadas" (RAMOS, 2001, p. 21). Inovações físico-químicas, mecânicas e biológicas anexadas ao território brasileiro, configurou às práticas agrícolas um padrão parecido ao padrão industrial, onde as máquinas passaram a comandar o processo produtivo.

\footnotetext{
${ }^{4}$ Algumas culturas ligadas ao mercado interno passavam por processamento antes de chegar aos consumidores.
} 
O crescimento da utilização desses novos objetos técnicos foi provocado por vários incentivos governamentais - créditos - realizados a partir de meados da década de 1960. Com suas taxas de juros abaixo da inflação, esses créditos foram assegurados via SNCR, que junto com a Reforma do Sistema Financeiro - articulada pelo Banco Central brasileiro - estabeleceram o asseguramento da canalização para a agricultura de parte dos recursos captados pelos bancos (principalmente Banco do Brasil, via CREAI) no país e no exterior. Através da venda no mercado financeiro internacional de papéis da dívida pública, a partir de acordos com o FMI e o Banco Mundial, consegue-se grande parte do capital para a modernização do campo brasileiro e realização do chamado milagre econômico.

Com esse capital, o Estado brasileiro

\begin{abstract}
subsidiou a compra de máquinas e equipamentos, insumos químicos; sementes melhoradas; custeou a produção, garantiu os preços mínimos, promoveu a eletrificação rural; construiu armazéns e silos para estocar a produção; subsidiou a exportação; isentou de impostos as indústrias nascentes associadas à agricultura moderna; promoveu o seguro agrícola etc. (ELIAS, 1996, p. 29-30).
\end{abstract}

São eventos que despontam anexando novos conteúdos ao território nacional. Para gerar a fluidez desejada principalmente pelos capitais forâneos financiadores da maior parte desse processo de modernização do setor agrícola brasileiro, internalizou-se assim no território nacional, na década de 1970, a "invenção do método de invenção" (SANTOS, 2002, p. 177). Com maior densidade no Centro-Sul do país, e em São Paulo principalmente, várias universidades, centros e institutos públicos de pesquisas foram implementados para atender as demandas por inovações nas cadeias produtivas. Sob a égide do mercado - igual aos países do centro do sistema -, as técnicas passaram a ser desenvolvidas massivamente em laboratórios científicos. Ampliou-se a divisão social, técnica e territorial do trabalho, tornando-se a intencionalidade do trabalho científico o paradigma para a modernização do território. Adentra o Brasil no período técnico-científico (Santos \& Silveira, 2001).

No final da década de 1970, desde o choque dos mercados e a elevação das taxas de juros internacionais em 1979, os países da América Latina passaram a enfrentar sérios problemas de divisas em relação ao exterior. Contudo, o padrão tecnológico agrícola instalado no território brasileiro já estava montado, o que permitiu à elite ruralista nacional enfrentar os reveses dos anos da década de 1980 e entrar os anos 1990 como o setor da economia mais preparado para enfrentar a competitividade neoliberal e manter forte seu lobby frente aos projetos de reestruturação do Estado. 


\section{2 - Reestruturação Produtiva na Agricultura}

A desestruturação do setor público foi progressivamente transferindo para o setor privado atividades que eram tradicionalmente atribuídas ao Estado. Financiamento da produção agrícola, políticas de estabilização da produção, a orientação da pesquisa tecnológica, a provisão de informações: no decorrer da década de 1990, essas atividades passaram a ser articuladas pelos atores do mercado, ficando o Estado com a incumbência de principalmente fiscalizar todo esse processo (Farina, 1996).

Grandes agroindústrias, grupos financeiros e empresas de insumos e máquinas, de maneira integrada, começam a assumir a maior parte do financiamento agrícola, onde novos instrumentos financeiros começam a surgir como forma de viabilizar a produção e a comercialização de produtos agropecuários. Adiantamento de Contratos de Câmbio (ACC), Cédula do Produtor Rural (CPR), Finame Agrícola, Contrato de Investimento Coletivo (CIC) e Pregões Eletrônicos aparecem no decorrer da década de 1990 - e adentram os anos 2000 como as principais fontes alternativas de investimento e custeio da atividade agrícola moderna no Brasil. Somente como avalista de parte desse capital, nesse cenário de escassez do crédito rural oficial, o Estado, através do Banco do Brasil e do BNDES (Banco Nacional de Desenvolvimento Econômico e Social), passou a direcionar recursos a taxas de juros favorecidas,

\footnotetext{
apenas à agricultura de baixa renda, através de programas especiais, como o Programa Nacional da Agricultura Familiar (PRONAF), o Programa de Geração de Emprego e Renda (PROGER) e o Programa Especial de Crédito para a Reforma Agrária (PROCERA). (BELIK \& PAULILLO, 2001, p.14).
}

Desarticulada as amarrações do momento anterior, coloca-se como desafio, para enfrentar a concorrência globalizada, a construção de novos arranjos organizacionais. Controlados cada vez mais por atores internacionais, modernizam-se os parques agroindustriais, construindo plantas padronizadas com as novas tecnologias da informação. Aprofundam-se os investimentos em inovações físico-químicas, mecânicas e biotecnológicas, expandindo a porção do espaço geográfico brasileiro definida como meio técnico-científicoinformacional (Elias, 1996).

Resultado desse esforço, a agricultura no Brasil passa a se destacar como uma das mais produtivas do mundo. Aumentando sua representação no PIB nacional entre 1990 e 2004, o setor agrícola, através de complexos agroindustriais como o do algodão, da cana-de-açúcar, de cereais e oleaginosas, de frutas e de carnes bovina, suína e de aves, alcançou altos índices de 
produtividade e competitividade e conquistou mercados no exterior (Gonçalves \& Souza \& Vicente, 2004).

\section{3 - As exportações brasileiras nos agronegócios em 2008}

$\mathrm{Na}$ última década, o saldo comercial dos agronegócios brasileiros se apresentou sempre positivo. Isso nos possibilita concordar que “... o desempenho da balança comercial brasileira está diretamente associado ao desempenho do principal segmento econômico nacional, representado pelos agronegócios” (SOUZA \& GONÇALVES, 2008, p. 05).

Assim, analisando 2008, presenciamos que as exportações brasileiras atingiram este ano o montante de US\$197,9 bilhões, o que significou um crescimento de 23,2\% relacionado ao valor das vendas externas ocorridas no ano de 2007. Oriundos dos agronegócios foram encaminhados ao mercado internacional produtos no valor de US\$ 76,1 bilhões, retratando entre 2007 e 2008 uma variação positiva de $23 \%$, o que representou 38,4\% nas exportações totais do Brasil (Tabela 1). Essa configuração sustenta o papel histórico do Brasil como um dos grandes exportadores dos agronegócios no mundo, configurando-se como um dos países de agricultura desenvolvida.

Ao examinar as exportações dos agronegócios brasileiros, registra-se entre os 10 principais destinos para o ano de 2008, respectivamente, os seguintes mercados: União Européia $^{5}$, China, Estados Unidos, Rússia, Venezuela, Japão, Argentina, Hong Kong, Arábia Saudita e Paraguai, que juntos atingem US\$ 54,4 bilhões ou 71,4\% do total exportado. Destacam-se nesse grupo a ascensão da China para a $2^{\mathrm{a}}$ posição entre os maiores mercados consumidores dos produtos dos agronegócios brasileiros (superando os Estados Unidos) e a quase duplicação do montante direcionado à Venezuela (Tabela 1), que junto ao Paraguai e Argentina incrementam a fatia dos produtos brasileiros no mercado sul-americano.

Uma observação importante que se explicita é o aprofundamento da desconcentração dos destinos dos produtos dos agronegócios do Brasil entre os 30 principais mercados compradores de nossas mercadorias do campo (Tabela 1). Com os crescimentos observados nas exportações para Cuba (87,7\%), Angola (65,8\%), Austrália (62,7\%), Tailândia (60,2\%) e

\footnotetext{
5 A União Européia é um bloco econômico, com união aduaneira e Política Agrícola Comum (PAC), formado por 27 países com uma população estimada em 500 milhões de habitantes.
} 
Marrocos $(45,7 \%)$ se têm alguns exemplos dessa acentuação da diversidade de parceiros alcançada nesse momento recente. As quedas sucessivas dos direcionamentos aos estadunidenses e a redução nos acréscimos nos dois últimos anos das vendas ao mercado europeu $^{6}$ - mesmo com a União Européia se mantendo na liderança dos destinos da produção agronegócios com $31,7 \%$ de toda nossa exportação sendo destinada para dentro de suas fronteiras - reforçam essa descentralização do comércio exterior dos agronegócios brasileiros.

Dentre os 30 principais destinos das exportações dos agronegócios brasileiros, presenciam-se variações importantes no perfil de agregação de valor no ano de 2008 . Representando 52,3\% dos direcionamentos dos agronegócios ao exterior, os produtos básicos apresentam na Tailândia (94,5\%), Hong-Kong (81,6\%), Coréia do Sul (74,8\%), China (72,2\%), Japão $(71,4 \%)$, Indonésia $(71,4 \%)$ e Arábia Saudita $(71,4 \%)$ os rumos mais densos de seu escoamento. Os produtos semimanufaturados contabilizaram $17 \%$ do volume das exportações - com Malásia (68,3\%) e Nigéria (54,9\%) absorvendo em suas importações dos agronegócios brasileiros mais da metade de seus volumes nesta fatia da produção - e os produtos manufaturados, com $29,3 \%$ das transações dos agronegócios realizado com o mercado externo, apresentaram no Paraguai (89,3\%), Chile (83,2\%), Argentina $(83,1 \%)$, México (72,2\%), Uruguai (71,8\%), Colômbia (70\%) e os Estados Unidos $(57,7 \%)$ as principais economias compradoras de suas mercadorias. Continua-se aquilo que já vinha acontecendo, onde "nota-se que na maior parte dos países que compram produtos manufaturados dos agronegócios brasileiros estão localizados no continente americano, enquanto os que compram produtos básicos na maioria são países asiáticos" (ÂNGELO \& GONÇALVES \& PINATTI, 2008, p.03).

\footnotetext{
${ }^{6}$ Os dados para a análise das variações entre 2006 e 2007 podem ser encontrados em ÂNGELO, J. A. \& GONÇALVES, J. S. \& PINATTI, E. Destinos das Exportações dos Agronegócios Brasileiros de 2007 v.3, n.3, março de 2008, Análises e Indicadores do Agronegócio, Instituto de Economia Agrícola (http://iea.sp.gov.br).
} 


\begin{tabular}{|c|c|c|c|c|c|c|c|c|c|c|}
\hline \multirow{2}{*}{$\begin{array}{l}\text { Posição } \\
\text { nos } \\
\text { Agrone- } \\
\text { gócios }\end{array}$} & \multirow{2}{*}{ Destino } & \multirow{2}{*}{$\begin{array}{l}\text { Total geral } \\
\text { exportado } \\
2008 \\
\text { (US\$ milhão) } \\
\text { ( A ) }\end{array}$} & \multicolumn{2}{|c|}{$\begin{array}{l}\text { Exportação } \\
\text { agronegócios } \\
\text { (US\$ milhão) }\end{array}$} & \multirow{2}{*}{$\begin{array}{l}\text { Variação } \\
(\%) \\
\\
(\text { C / B ) }\end{array}$} & \multicolumn{2}{|c|}{$\begin{array}{l}\text { Participação } \\
(\%)\end{array}$} & \multicolumn{2}{|c|}{$\begin{array}{l}\text { Agronegócios } \\
\text { de Valor (\%) }\end{array}$} & Agregação \\
\hline & & & $\begin{array}{l}2007 \\
\text { ( B ) }\end{array}$ & $\begin{array}{l}2008 \\
(\mathrm{C})\end{array}$ & & $(C / A)$ & $(\mathrm{C} / \Sigma \mathrm{C})$ & Básico & $\begin{array}{l}\text { Semi- } \\
\text { manu- } \\
\text { faturad } \\
\text { o }\end{array}$ & $\begin{array}{l}\text { Manufa } \\
\text {-turado }\end{array}$ \\
\hline 1 & União Européia & 46.367 & 21.232 & 24.174 & 13,86 & 52,14 & 31,75 & 57,84 & 14,87 & 27,30 \\
\hline 2 & $\begin{array}{l}\text { China } \\
\text { Estados }\end{array}$ & 16.403 & 4.691 & 7.972 & 69,95 & 48,60 & 10,47 & 72,20 & 25,21 & 2,58 \\
\hline 3 & Unidos & 27.423 & 6.841 & 6.615 & $-3,29$ & 24,12 & 8,69 & 22,44 & 19,88 & 57,68 \\
\hline 4 & Rússia & 4.653 & 3.402 & 4.218 & 23,97 & 90,65 & 5,54 & 67,34 & 27,79 & 4,86 \\
\hline 5 & Venezuela & 5.150 & 1.375 & 2.628 & 91,22 & 51,04 & 3,45 & 51,91 & 4,65 & 43,44 \\
\hline 6 & Japão & 6.115 & 1.768 & 2.464 & 39,33 & 40,29 & 3,24 & 71,40 & 11,51 & 17,09 \\
\hline 7 & Argentina & 17.606 & 1.947 & 2.182 & 12,07 & 12,39 & 2,87 & 10,68 & 6,20 & 83,12 \\
\hline 8 & Hong Kong & 1.811 & 1.210 & 1.634 & 35,05 & 90,24 & 2,15 & 81,61 & 14,23 & 4,16 \\
\hline 9 & Arábia Saudita & 2.564 & 998 & 1.446 & 44,78 & 56,39 & 1,90 & 71,48 & 10,74 & 17,79 \\
\hline 10 & Paraguai & 2.488 & 678 & 1.102 & 62,71 & 44,32 & 1,45 & 9,55 & 1,08 & 89,37 \\
\hline 11 & Coréia do Sul & 3.119 & 852 & 1.021 & 19,84 & 32,73 & 1,34 & 74,87 & 10,79 & 14,33 \\
\hline 12 & Irã & 1.133 & 1.571 & 929 & $-40,86$ & 81,99 & 1,22 & 60,25 & 35,27 & 4,48 \\
\hline 13 & $\begin{array}{l}\text { Tailândia } \\
\text { Emirados }\end{array}$ & 1.566 & 570 & 913 & 60,20 & 58,32 & 1,20 & 94,54 & 2,74 & 2,72 \\
\hline 14 & Árabes & 1.323 & 821 & 777 & $-5,35$ & 58,72 & 1,02 & 67,24 & 11,39 & 21,37 \\
\hline 15 & Egito & 1.409 & 698 & 777 & 11,33 & 55,15 & 1,02 & 44,97 & 44,27 & 10,76 \\
\hline 16 & Angola & 1.975 & 409 & 678 & 65,86 & 34,35 & 0,89 & 31,66 & 1,36 & 66,98 \\
\hline 17 & África do Sul & 1.755 & 685 & 674 & $-1,61$ & 38,40 & 0,88 & 28,02 & 7,10 & 64,88 \\
\hline 18 & Chile & 4.792 & 467 & 589 & 26,10 & 12,29 & 0,77 & 11,39 & 5,34 & 83,27 \\
\hline 19 & Canadá & 1.866 & 579 & 575 & $-0,71$ & 30,80 & 0,75 & 22,60 & 46,07 & 31,33 \\
\hline 20 & Argélia & 632 & 429 & 549 & 27,92 & 86,72 & 0,72 & 40,24 & 43,82 & 15,94 \\
\hline 21 & Indonésia & 1.143 & 434 & 524 & 20,75 & 45,85 & 0,69 & 71,45 & 20,04 & 8,51 \\
\hline 22 & México & 4.281 & 464 & 494 & 6,46 & 11,53 & 0,65 & 13,38 & 14,35 & 72,27 \\
\hline 23 & Uruguai & 1.644 & 374 & 482 & 28,90 & 29,30 & 0,63 & 20,28 & 7,92 & 71,81 \\
\hline 24 & Nigéria & 1.536 & 384 & 481 & 25,17 & 31,30 & 0,63 & 7,16 & 54,90 & 37,93 \\
\hline 25 & Suiça & 1.460 & 399 & 477 & 19,33 & 32,64 & 0,63 & 52,10 & 14,76 & 33,13 \\
\hline 26 & Colômbia & 2.295 & 354 & 445 & 25,75 & 19,38 & 0,58 & 21,16 & 8,80 & 70,04 \\
\hline 27 & Marrocos & 511 & 299 & 435 & 45,70 & 85,11 & 0,57 & 35,99 & 46,94 & 17,07 \\
\hline 28 & Malásia & 877 & 392 & 417 & 6,26 & 47,52 & 0,55 & 20,85 & 68,38 & 10,77 \\
\hline 29 & Cuba & 527 & 222 & 417 & 87,97 & 79,09 & 0,55 & 37,47 & 9,82 & 52,71 \\
\hline \multirow[t]{4}{*}{30} & Austrália & 1.253 & 233 & 378 & 62,76 & 30,21 & 0,50 & 51,93 & 11,06 & 37,01 \\
\hline & Subtotal & 165.675 & 54.775 & 66.465 & 21,34 & 40,12 & 87,29 & 53,08 & 17,57 & 29,34 \\
\hline & $\begin{array}{l}\text { Demais } \\
\text { destinos }\end{array}$ & 32.268 & 7.103 & 9.676 & 36,23 & 29,99 & 12,71 & 47,04 & 13,32 & 39,64 \\
\hline & Total & 197.942 & 61.878 & 76.141 & 23,05 & 38,47 & 100,00 & 52,32 & 17,03 & 30,65 \\
\hline
\end{tabular}

As exportações dos agronegócios brasileiros em 2008, tendo em conta as 30 principais destinações, ao somarem US\$ 66,5 bilhões, representaram 87,4\% das vendas setoriais totais, participação um pouco menor que a verificada em 2007 quando somaram US\$ 54,8 bilhões e corresponderam a 88,7\% das transações. Esses mesmos indicadores, em 2006 atingiam US\$ 
46,1 bilhões, quando o percentual correspondia a 88,4\%. Dessa maneira, conquanto as vendas externas setoriais totais tenham sido ampliadas de US\$ 52,0 bilhões em 2006 para US\$ 61,9 bilhões em 2007 e US\$ 76,1 bilhões em 2008, há variação menor de apenas 0,7 ponto percentual na representatividade dos 30 principais destinos, o que indica pouca alteração na expressão conjunta das principais economias importadoras de produtos dos agronegócios brasileiros. Tanto assim que comparando 2008 com 2007, entram para a lista dos principais destinos apenas a Austrália e Cuba e saem Cingapura e Turquia, sem alterar significativamente o quadro geral ${ }^{2}$.

A análise dos 5 principais destinos das exportações brasileiras mostra que, conquanto tenha se ampliado os destinos, as mesmas se mostram ainda muito concentradas. Tanto assim que o conjunto desses 5 mercados que compraram US\$33,5 bilhões em 2006 (64,5\%), em 2007 aumentou em valor para US\$ 37,5 bilhões mas recuou em percentual para 60,7\%, tendência que teve continuidade em 2008, quando rendeu US\$ 45,6 bilhões com representatividade ainda menor (59,9\%). Isso decorre como será visto de que a União Européia teve incrementos inferiores aos dos demais destinos (Tabela 1). Importantes no último ano foram as medidas protecionistas argentinas visando frear a entrada de produtos brasileiros, com o que esse parceiro latino-americano deixou o grupo dos 5 principais compradores dos agronegócios nacionais, lugar ocupado pela Venezuela, tendo ainda os portenhos sido superados pelo Japão.

Enquanto principal mercado de destino dos produtos dos agronegócios brasileiros, a União Européia tem nos produtos básicos o maior percentual de sua demanda $(57,8 \%)$. O grupo Cereais, Leguminosas e Oleaginosas apresentou um crescimento em sua densidade de negócios entre 2007 e 2008 em 32,9\%, tendo neste grupo a soja concentrando $90 \%$ do montante de seu valor. Café, Frutas e Produtos Florestais também tiveram ascensão em seus volumes transacionados do Brasil ao Bloco Europeu, declinando somente o comércio de bovídeos tendo em vista o embargo europeu à carne bovina paulista em função do foco de aftosa detectado no Mato Grosso do Sul em 2005 e a intensa pressão dos irlandeses uma vez que estes foram os maiores perdedores com a entrada da carne brasileira no mercado europeu após o "mal da vaca louca" (Tabela 1).

A China, o segundo maior comprador dos produtos do agronegócio brasileiro, concentra suas compras na soja (produtos básicos) e nos produtos florestais (semimanufaturados) representando quase 90\% do total exportado. Em 2008 as exportações para China tiveram um crescimento de $70 \%$ em comparação com ano anterior, esse 
incremento deve-se principalmente ao aumento do preço da soja no mercado internacional verificados até julho de 2008, já que o volume exportado de soja em grão cresceu no mesmo período $17,4 \%$ com 11,8 milhões de toneladas.

No que se refere aos Estados Unidos da América (E.U.A.), oriundo prioritariamente da crise financeira que abala a principal economia do mundo nos últimos anos presenciamos um menor poder de compra da população daquele país ocasionado pelo aumento do desemprego de seus cidadãos. Sendo assim, mesmo com os aumentos das importações feitas junto ao Brasil de café, cana-de-açúcar e seus derivados, o total da exportação dos agronegócios feitos pelos estadunidenses variou negativamente em 3,3\% (Tabela 2), acrescentando assim para os dois últimos anos a redução de 7,2\% nas compras norte americanas de 2007.

Para a Rússia, diferente dos mercados analisados acima, entre 2007 e 2008 se apresentou acréscimos em todos os grupos de produtos dos agronegócios analisados. Concentrada basicamente nos produtos básicos de carnes (bovinas, suínas e de frangos), que juntos representam $61,4 \%$ do total, e no açúcar semi-processado, que atinge $27,5 \%$ de toda sua importação. Potencializada pelo montante de reservas adquiridas nos anos de bonança dos preços altos de petróleo e gás natural principalmente - seus principais produtos de exportação - a economia russa, ao contrário dos norte-americanos, possibilitou um revigoramento do poder de compra de sua população, aumentando entre outros itens sua fatia nos produtos dos agronegócios exportados pelo Brasil.

Tabela 1 - Principais destinos das exportações brasileiras dos agronegócios, por grupo, anos 2007 e 2008 Destino: União Européia Posição Grupos 2007 2008 Var.(\%) 


\begin{tabular}{|c|c|c|c|c|c|c|}
\hline & & & & \multirow[b]{2}{*}{$2008 / 07$} \\
\hline & & US\$ (1.000) & part. \% & US\$ (1.000) & part.\% & \\
\hline 1 & Soja + (Oleag.,Cereais,Leg.) & 6.647 .155 & 31,31 & 8.838 .196 & 36,56 & 32,96 \\
\hline 2 & Produtos Florestais & 3.410 .741 & 16,06 & 3.664 .404 & 15,16 & 7,44 \\
\hline 3 & Café e Estimulantes & 2.156 .444 & 10,16 & 2.679 .600 & 11,08 & 24,26 \\
\hline 4 & Bovídeos & 2.726 .941 & 12,84 & 2.098 .581 & 8,68 & $-23,04$ \\
\hline \multirow[t]{4}{*}{5} & Frutas & 2.074 .504 & 9,77 & 2.085 .472 & 8,63 & 0,53 \\
\hline & Subtotal & 17.015 .786 & 80,14 & 19.366.254 & 80,11 & 13,81 \\
\hline & Demais grupos & 4.216 .040 & 19,86 & 4.807 .873 & 19,89 & 14,04 \\
\hline & Total & 21.231 .826 & 100,00 & 24.174 .127 & 100,00 & 13,86 \\
\hline \multicolumn{7}{|c|}{ Destino: China } \\
\hline \multirow{2}{*}{ Posição } & \multirow{2}{*}{ Grupos } & \multicolumn{2}{|l|}{2007} & \multicolumn{2}{|l|}{2008} & \multirow{2}{*}{$\begin{array}{l}\text { Var.(\%) } \\
2008 / 07\end{array}$} \\
\hline & & US\$ (1.000) & part. $\%$ & US\$ (1.000) & part. \% & \\
\hline 1 & Soja + (Oleag.,Cereais,Leg.) & 3.155 .216 & 67,27 & 6.163 .452 & 77,32 & 95,34 \\
\hline 2 & Produtos Florestais & 578.631 & 12,34 & 835.772 & 10,48 & 44,44 \\
\hline 3 & Bovídeos & 491.230 & 10,47 & 375.376 & 4,71 & $-23,58$ \\
\hline 4 & Fumo & 271.340 & 5,78 & 367.315 & 4,61 & 35,37 \\
\hline \multirow[t]{4}{*}{5} & Frutas & 66.027 & 1,41 & 70.287 & 0,88 & 6,45 \\
\hline & Subtotal & 4.562 .445 & 97,27 & 7.812 .203 & 98,00 & 71,23 \\
\hline & Demais grupos & 128.206 & 2,73 & 159.380 & 2,00 & 24,32 \\
\hline & Total & 4.690 .651 & 100,00 & 7.971 .582 & 100,00 & 69,95 \\
\hline \multicolumn{7}{|c|}{ Destino: Estados Unidos } \\
\hline \multirow{2}{*}{ Posição } & \multirow{2}{*}{ Grupos } & \multicolumn{2}{|l|}{2007} & \multicolumn{2}{|l|}{2008} & \multirow{2}{*}{$\begin{array}{l}\text { Var.(\%) } \\
2008 / 07\end{array}$} \\
\hline & & US\$ (1.000) & part. \% & US\$ (1.000) & part. \% & \\
\hline 1 & Produtos Florestais & 2.209 .729 & 32,30 & 1.978 .675 & 29,91 & $-10,46$ \\
\hline 2 & Bovídeos & 1.317 .377 & 19,26 & 995.206 & 15,04 & $-24,46$ \\
\hline 3 & Café e Estimulantes & 774.804 & 11,33 & 923.194 & 13,96 & 19,15 \\
\hline 4 & Cana e Sacarídeas & 471.350 & 6,89 & 845.841 & 12,79 & 79,45 \\
\hline 5 & Frutas & 738.130 & 10,79 & 588.609 & 8,90 & $-20,26$ \\
\hline & Subtotal & 5.511 .391 & 80,57 & 5.331 .525 & 80,59 & $-3,26$ \\
\hline & Demais grupos & 1.329 .111 & 19,43 & 1.283 .730 & 19,41 & $-3,41$ \\
\hline & Total & 6.840 .501 & 100,00 & 6.615 .255 & 100,00 & $-3,29$ \\
\hline Destino: & sia & & & & & \\
\hline Posição & Grupos & 2007 & & 2008 & & Var.(\%) \\
\hline rusiçau & Gipos & US\$ (1.000) & part. \% & US\$ (1.000) & part. $\%$ & $2008 / 07$ \\
\hline 1 & Bovídeos & 1.016 .635 & 29,88 & 1.500 .833 & 35,58 & 47,63 \\
\hline 2 & Cana e Sacarídeas & 1.047 .751 & 30,79 & 1.157 .724 & 27,45 & 10,50 \\
\hline 3 & Suínos e Aves & 980.351 & 28,81 & 1.086 .861 & 25,77 & 10,86 \\
\hline 4 & Fumo & 115.008 & 3,38 & 156.635 & 3,71 & 36,20 \\
\hline 5 & Soja + (Oleag.,Cereais,Leg.) & 82.509 & 2,42 & 138.794 & 3,29 & 68,22 \\
\hline & Subtotal & 3.242 .253 & 95,29 & 4.040 .847 & 95,80 & 24,63 \\
\hline & Demais grupos & 160.205 & 4,71 & 177.294 & 4,20 & 10,67 \\
\hline & Total & 3.402 .459 & 100,00 & 4.218 .140 & 100,00 & 23,97 \\
\hline Destino: & ezuela & & & & & \\
\hline Posicão & Grupos & 2007 & & 2008 & & Var. $(\%)$ \\
\hline rosiçau & Gipus & US\$ (1.000) & part. $\%$ & US\$ (1.000) & part. $\%$ & $2008 / 07$ \\
\hline 1 & Bovídeos & 466.448 & 33,93 & 1.151 .036 & 43,79 & 146,77 \\
\hline 2 & Suínos e Aves & 219.534 & 15,97 & 566.993 & 21,57 & 158,27 \\
\hline 3 & Soja + (Oleag.,Cereais,Leg.) & 107.235 & 7,80 & 297.111 & 11,30 & 177,06 \\
\hline 4 & Bens de capital e insumos & 189.904 & 13,82 & 158.836 & 6,04 & $-16,36$ \\
\hline 5 & Produtos Florestais & 124.026 & 9,02 & 147.301 & 5,60 & 18,77 \\
\hline & Subtotal & 1.107 .147 & 80,54 & 2.321 .278 & 88,31 & 109,66 \\
\hline & Demais grupos & 267.472 & 19,46 & 307.207 & 11,69 & 14,86 \\
\hline & Total & 1.374 .619 & 100,00 & 2.628 .485 & 100,00 & 91,22 \\
\hline
\end{tabular}

Fonte: Elaborada pelo Instituto de Economia Agrícola, a partir de dados básicos da SECEX/MDIC.

A Venezuela, também beneficiada pela supervalorização dos produtos petrolíferos que representam $90 \%$ de sua cesta de produtos vendidos no mercado externo - foi o país que mais acrescentou entre 2007 e 2008 produtos dos agronegócios brasileiros em suas 
importações, com um crescimento de 91,2\%. O grupo de bovinos é o principal item na pauta de exportação para a Venezuela com valor de US\$ 1,15 bilhão e participação de 43,8\% dos agronegócios, distribuídos quase uniformemente entre carne, produtos lácteos e animais vivos. Porém, a carne de frango foi a fonte de proteína animal que sozinha teve a maior participação no valor das vendas com US\$ 531 milhões.

\section{4 - Considerações Finais}

Sendo assim, com vendas que superaram os US\$ 75 bilhões, o Brasil em 2008 bateu um novo recorde em suas exportações dos agronegócios. Diversificando ainda mais os destinos da produção dos agronegócios, o Brasil se destacou no comércio externo do setor principalmente com a soja, madeira, carne de frango, açúcar, carne bovina, couro, álcool e laranja. Com a crise deflagrada no final do primeiro semestre de 2008, para o ano de 2009, a continuidade da expansão das exportações dos agronegócios verificada durante todos os anos iniciais deste século XXI, poderá estar comprometida com reversão da tendência até então verificada.

A queda nos preços da maioria das commodities da agricultura nacional, ainda que a desvalorização cambial possa elevar suas cotações em moeda brasileira - mas essa mudança no câmbio afeta para cima também os custos de transação pagos em dólar -, associada com a escassez de crédito, ainda que tenha havido um notável esforço das autoridades governamentais nacionais em garantir recursos para financiar as vendas externas e a expectativa de redução da demanda agregada de bens de consumo gerada pelo aumento galopante do desemprego no mundo são variáveis que colocam a exportação em 2009 abaixo das previsões feitas antes do aprofundamento da crise.

Entretanto, torna-se relevante salientar que isso não necessariamente significa uma piora dos resultados da balança comercial dos agronegócios, dado que a desvalorização cambial encarecendo os produtos estrangeiros acaba por reduzir as importações, que vêm caindo mais que as exportações, redundando em saldos comerciais iguais ou crescentes. Isso pode não ser efetivado somente se a crise atingir patamares mais dramáticos de queda da demanda agregada por produtos dos agronegócios, como os gêneros de primeira necessidade.

A questão mais relevante consiste no fato de que preços menores em dólar e a pressão

de custos dos insumos importados - por exemplo, o Brasil importa três quartos dos fertilizantes que consome-, podem afetar de forma drástica a competitividade relativa de 
muitas cadeias de produção da agricultura nacional, colocando em questão opções tidas como inquestionáveis até pouco tempo atrás. As perspectivas de exportação de álcool estão nesse contexto, porque uma coisa é pensar ampliar mercados para biocombustíveis com petróleo superando US\$ 150/barril como no primeiro semestre de 2008, outra consiste em pensar essa estratégia com o tradicional combustível fóssil vendido a menos de US\$ 50/barril como no início de 2009.

Ademais, como se viu na análise dos destinos das exportações, o petróleo gerava cambiais para dois dos 5 principais importadores dos agronegócios brasileiros (Rússia e Venezuela). Sem as receitas do petróleo como irão se comportar esses mercados. Noutras palavras, em 2009 ainda não se conformaram a formação de expectativas sólidas sobre os rumos do comércio mundial, o que já se tem nítido é que essa crise estrutural do capitalismo, se não significa o fim da história para esse modo de produção, não será superada sem alterações profundas nas relações internacionais, de regulação de toda ordem.

O próprio pacote recente do novo Governo dos EUA inclui o temido "by América", que privilegia produtos norte-americanos nas compras governamentais. Ou seja, as políticas deixam um pouco de lado as questões climáticas para focarem o emprego e também as discussões globais para se atentar para as locais, ainda que isso implique em protecionismo. A preocupação com a fome do mundo manifestada quando da "crise de alimentos" do primeiro semestre de 2008 deixou a pauta das discussões. Para 2009 ainda não se tem claro os desdobramentos da crise e qual a magnitude dos seus efeitos sobre o comércio mundial.

\section{Bibliografia:}

ÂNGELO, J. A. \& GONÇALVES, J. S. \& PINATTI, E. "Destinos das Exportações dos Agronegócios Brasileiros de 2007”. v.3, n.3, março de 2008, Análises e Indicadores do Agronegócio, Instituto de Economia Agrícola (http://iea.sp.gov.br).

BELIK \& PAULILLO. “O Financiamento da Produção Agrícola Brasileira na década de 90: Ajustamento e Seletividade" publicado em Leite, S. (org.) Políticas Públicas e Agricultura no Brasil. Editora Universidade UFRGS, pp. 95-120, 2001.

ELIAS, D. "Meio Técnco-Científico-Informacional e Urbanização na região de Ribeirão Preto (SP)”. Tese de Doutorado. Departamento de Geografia. FFLCH. USP. São Paulo, 1996. 
FARINA, E. M. M. Q. "Reflexões sobre a desregulamentação e sistemas agroindustriais: a experiencia brasileira”. Tese de Livre-Docência, FEA, USP, São Paulo, 1996.

GONÇALVES, J. S. \& SOUZA, S. A. M. \& VICENTE, J. R. “Comércio Exterior dos Agronegócios Brasileiros: desempenho dos principais grupos de cadeias de produção, 1997 2003”. Informações Econômicas, v. 34, n. 12, dez. 2004, Secretaria da Agricultura e Abastecimento do estado de São Paulo, São Paulo, 2004.

KAGEYAMA, A. “O Novo Padrão Agrícola Brasileiro: do Complexo Rural aos Complexos Agroindustriais”. In: Delgado, G. C. Agricultura e Políticas Públicas. págs. 113-223. IPEA. Brasília, 1990.

RAMOS, S. F. "Uso do território brasileiro e sistemas técnicos agrícolas: a fruticultura irrigada em Petrolina (PE)/Juazeiro (BA)". Dissertação de Mestrado, FFLCH, USP, São Paulo, 2001.

SANTOS, M. "Natureza do Espaço: técnica e tempo, razão e emoção". Editora da Universidade de São Paulo. São Paulo, 2002.

SANTOS, M. \& SILVEIRA, M. L. “O Brasil: Território e Sociedade no Início do Século XXI”. Editora Record. Rio de Janeiro, 2001.

SOUZA, S. A. M. \& GONÇALVES, J. S. "Comportamento da Balança Comercial dos Agronegócios Paulista e Brasileiro no Período 1997-2008”. v.4, n.2, março de 2009, Análises e Indicadores do Agronegócio, Instituto de Economia Agrícola (http://iea.sp.gov.br). 